\title{
Potencialidades não convencionais no design gráfico contemporâneo Um estudo de caso de LULULUX
}

Guilherme Paranhos Paes é pesquisador na área de design gráfico com foco na linguagem visual do design contemporâneo, atualmente é mestrando no PPG Design - Universidade Anhembi Morumbi (UAM).<g-paranhos@hotmail.com> ORCID: 0000-0002-4350-3690
Resumo $O$ presente artigo tem como objetivo analisar o projeto gráfico denominado LULULUX (2014) que foi realizado pelo designer gráfico brasileiro Gustavo Piqueira. LULULUX é um conjunto narrativo de jantar onde o designer se utiliza do suporte material de guardanapos, porta-copos e jogo americano para a conjunção de proposição de um livro. A abordagem deste projeto explana sobre os limites do livro impresso, tanto em sua materialidade quanto suas composições visuais e funções, gerando um paralelo e um questionamento acerca da convencionalidade do design editorial contemporâneo, expondo novas perspectivas e potencias para o livro impresso em uma possibilidade de um objeto material de grande valor narrativo e conceitual.

Palavras chave Design gráfico, Funções do livro, Materialidade do livro, LULULUX. 
Mirtes Marins de Oliveira é docente e pesquisadora no PPG Design - Universidade Anhembi Morumbi. É curadora e crítica de Arte e Design.

$<$ mirtescmoliveira@gmail.com> ORCID: 0000-0002-7132-0875

\section{Non-conventional potentials in the contemporary graphic design A LULULUX case study}

\begin{abstract}
This article aims to analyze the graphic project called LULULUX (2014), realized by the Brazilian graphic designer Gustavo Piqueira. LULULUX is a narrative on a dinner set where the Piqueira uses as support napkins, cup holders and placemats as a book's proposition. The project points to the limits of the printed book, both in its materiality as well as its visual compositions and functions, generating a parallel and a questioning about the conventionality of contemporary editorial design, exposing new perspectives and strengths for the printed book in a possibility of an object material of great narrative and conceptual value.
\end{abstract}

Keywords Graphic design, Book functions, Book materiality, LULULUX.

\section{Potenciales no convencionales en eldiseño gráfico contemporáneo Un estudio de caso LULULUX}

ra em Artes - Instituto de Artes da UNESP.

Doutora em Comunicação - Escola de Comunicações e Artes da USP. Mestre em Artes Visuais - UNESP. Docente do Curso de Design do Instituto de Tecnologia Mauá.<agdarcarvalho@gmail.com> ORCID: 0000-0002-3604-2750

\begin{abstract}
Resumen Este artículo tiene como objetivo analizar el proyecto gráfico llamado LULULUX (2014) realizado por el diseñador gráfico brasileño Gustavo Piqueira. LULULUX es un conjunto narrativo donde el diseñador usa material de soporte para servilletas, portavasos y manteles para la proposición de un libro. El enfoque de este proyecto explica los límites de libro impreso, tanto en su materialidad como en sus composiciones y funciones visuales, generando un paralelo y un cuestionamiento sobre la convencionalidad del diseño editorial contemporáneo, exponer nuevas perspectivas $y$ fortalezas del libro impreso en la posibilidad de un objeto material de gran valor narrativo y conceptual.
\end{abstract}

Palabras clave Diseño gráfico, Funciones del libro, Materialidad del libro, LULULUX. 


\section{Introdução}

As formas dos artefatos não possuem um significado fixo, mas antes são expressivas de um processo de significação - ou seja, a troca entre aquilo que está embutido em sua materialidade e aquilo que pode ser depreendido delas por nossa experiência. (CARDOSO, 2016. p.35-36)

O livro pode se configurar de diversas formas, tamanhos, composições e funções. Dentro da enorme variedade de possibilidades de se compor um livro o aspecto físico deste objeto é papel fundamental para os significados que ele pode gerar. A materialidade dessa peça carrega a importância de caracterizá-lo como um objeto palpável, manipulável e real, esses atributos que o constituem são parte substancial da estrutura do projeto como um todo. Esta tangibilidade será discutida quanto aos seus limites, funções e possíveis elaborações.

LULULUX (2014) é uma narrativa impressa subdividida em 34 partes. Não se tratando, contudo, de 34 capítulos. Esse formato provoca a classificação de LULULUX como livro, pois suas peças se afastam do habitual códice e apresentam-se como um conjunto narrativo de jantar que contempla: 20 guardanapos, 06 jogos americanos e 08 porta-copos. Que podem tanto ser lidos quanto servidos à mesa de refeições, quando o leitor assim se propor em realizá-lo.

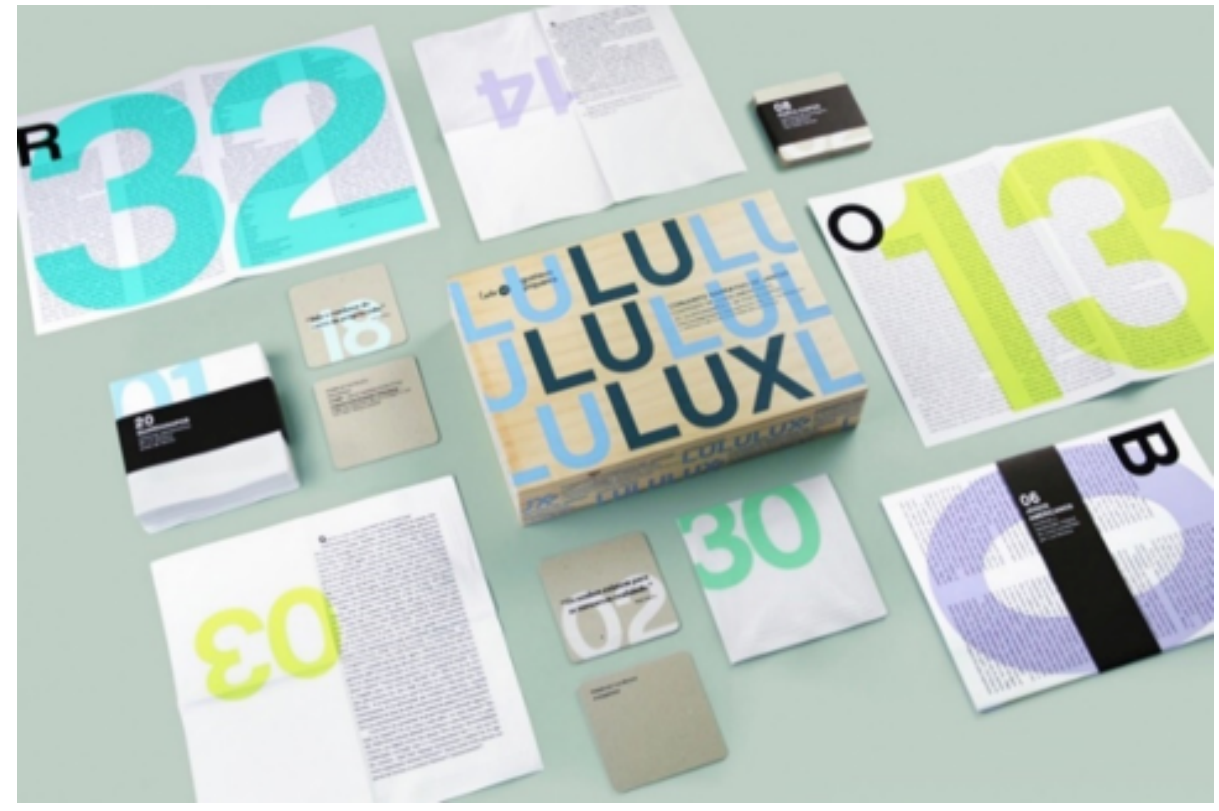

Fig 1. Conjunto de peças do livro

Fonte: www.lululux.com.br, 2019 
As partes componentes desse livro (figura 1) estão divididas em uma caixa de madeira pínus com 32,5 x 23,5 x 6,8 cm, impressa em serigrafia com duas cores; 08 porta-copos de papelão paraná com $10 \times 10 \mathrm{~cm}$ impressos em serigrafia com três cores; 06 jogos americanos de papel offset $20 \mathrm{~g}$ de formato fechado $21 \times 29,7 \mathrm{~cm}$ e aberto de $42 \times 29,7 \mathrm{~cm}$, impressos em duas cores de serigrafia e 20 guardanapos com o formato fechado de $14,5 \times 14,5$ $\mathrm{cm}$ e formato aberto $28,9 \times 29,1 \mathrm{~cm}$ impressos em serigrafia com três cores. Todas as cores utilizadas no projeto variam entre azul, roxo, amarelo e preto. As tecnologias utilizadas são de objetos materiais que foram reutilizados como suporte para a escrita do livro, tanto o modo de impressão quanto esses materiais possuem características referentes a produção analógica de um projeto de design.

O trabalho de Gustavo Piqueira à frente do escritório Rex Design (1997) e a partir de 2010 como Casa Rex, na qual ele é fundador, se situa em São Paulo e apresenta uma linguagem visual variada, presente em mais de seus 460 projetos premiados internacionalmente que mostram o quão diversificado pode ser o raio de atuação do designer e o quanto a produção pode se tornar múltipla.

Em mais de 20 livros publicados pode-se observar uma mistura de design, história, arte, literatura, os limites do livro impresso e um olhar para o cotidiano a fim de encontrar possibilidades narrativas tanto textuais quanto visuais, que resulta em narrativas contemporâneas que testam as fronteiras da linguagem. A exploração da materialidade marca presença em seus projetos levantando novas possibilidades para o livro impresso, se utilizando da combinação de materiais diversos, composições visuais múltiplas e de textos que são uma extensão da própria visualidade de seus livros.

O conjunto narrativo de jantar proposto em LULULUX ressignifica dois objetos e situações, o livro junto com o conjunto de jantar e a leitura em conjunto ao ato de se estar a mesa jantando que são distantes em suas aplicações. $O$ conjunto de jantar que aqui se caracteriza como o agrupamento de utensílios que podem ser usados a mesa em uma refeição sendo compostos por guardanapos, porta-copos e jogo americano ${ }^{1}$ e o livro, mas que agora recombinados possibilitam uma nova atuação. 0 projeto opera nessa nova perspectiva para o suporte narrativo de uma história. Traçando um paralelo com o livro convencional que se apresenta como um conjunto de folhas encadernadas em sequência e agrupadas por uma capa como apresenta HASLAM (2007), esta produção potencializa o meio físico e multifuncional de um objeto segundo CARDOSO (2016) e BOMFIM (1997), alavancando seus componentes tanto materiais como visuais a fim de propor uma nova concepção para o que se pode entender como suporte para uma história, estabelecendo assim um objeto que BORIS (2002) vai tratar como novo por não possuir parâmetros anteriores de comparação. 


\title{
Potencialidades não convencionais
}

Segundo Haslam (2007) é levantado algumas definições para a palavra livro a partir de um dicionário e uma enciclopédia:

\author{
O Concise Oxford Dictionary apresenta duas possibilidades: \\ “Tratado portátil manuscrito ou impresso que preenche uma série de fo- \\ lhas encadernadas, vinculadas umas ás outras". \\ Composição literária que preenche um conjunto de folhas". \\ A Encyclopedia Britannica oferece por sua vez nas duas definições: \\ “Uma mensagem escrita (ou impressa) de tamanho considerável, desti- \\ nada a circulação pública e registrada em materiais leves, porém durá- \\ veis o bastante para oferecerem uma relativa portabilidade". \\ "Instrumento de comunicação". \\ (HASLAM, 2007. p.8).
}

O livro dito como convencional, ou seja, aquele composto de forma que as palavras e frases são alinhadas linearmente sobre uma folha de papel encadernados em um códice que podem se apresentar de diversos tamanhos, tipos de impressão e materiais. Este possui uma abordagem de design focado na leitura do usuário a fim de se compor um objeto de fácil manuseio, transporte e visualização de suas informações. Esta normatização quanto a estas características identificam um objeto como livro.

O trabalho mais comum e corriqueiro do designer como formador deste produto está presente no desenvolvimento de aspectos formais de composição visual (tipografias, cores, diagramação e imagens) e os materiais empregados em sua fabricação. Desta forma, as escolhas propostas pelo designer junto a uma equipe de editoração, formatam o aspecto físico do livro que será propagado e vendido no mercado editorial.

Devido as inúmeras modificações no cenário comercial dos livros, quanto a expansão do meio digital tanto para a leitura como na compra, alguns comportamentos modificaram o tratamento que esta peça pode ter. A massificação do digital alterou a perspectiva da produção do livro e os seus meios de atuação, a compra não é mais feita somente presencialmente em uma livraria ou banca, mas por páginas online onde um acervo de busca se abre para o usuário. Logo alguns princípios básicos de muita importância como a capa que é um elemento indispensável para a venda do livro que irá fazer competição para outras capas dispostas nas prateleiras se torna questionável.

Outro prisma a ser observado é sobre a própria materialidade e tecnologia do próprio livro impresso, o mercado editorial se tornou mais competitivo devido a expansão do digital, mas as próprias soluções físicas do livro apresentam inquietações, as edições de luxo, edições limitadas e reedições 
abriram um novo entendimento sobre a atenção empregada na produção. o livro recentemente está além somente de seu miolo (páginas internas) ou de sua capa, ele se apresenta como ao longe de um livro em si, mas como um objeto complexo que pode carregar uma serie de artifícios tecnológicos e de soluções gráficas com muitos significados, como por exemplo o uso de janelas ${ }^{2}$ na capa, uma estrutura sanfonada para o seu códice, o uso de sobrecapas, capas cartazes e caixas são algumas soluções que atualmente são utilizadas em larga escala. Essas novas abordagens indicam as mudanças que estão acontecendo no mercado editorial em relação a estrutura física convencional do livro impresso, o desabrochar desses projetos geram um panorama promissor para as elaborações no design gráfico contemporâneo, onde a relação com o meio material é conduzida de novos significados.

Traçando os parâmetros acima e os colocando em paralelo ao projeto especifico a ser discutido nesse artigo, se exibe uma lacuna e uma questão se gera de quais são os possíveis limites do livro impresso? LULULUX é um exponencial nesta discussão por apresentar critérios quanto a sua materialidade que são totalmente desconexos com os padrões vigentes na editoração, padronização e produção do livro impresso contemporâneo.

Uma atuação mais ampla do que o convencional do design de livros contemporâneo implica em uma aproximação e observação da cultura $^{3}$ de seu tempo. "(...) o criador produtor se emancipa da demanda de um mercado e torna-se agente social. " (FALCÃO, 2019. p.110). Tendo a possibilidade de compreender a cultura e a sociedade que o cerca, pode-se estimular uma linguagem que tenha composições e elementos visuais que se articulem de forma mais ampla. Portanto, o designer pode atuar de forma perspicaz com o intuito de estimular os modelos visuais vigentes que não constroem pontes, mas restringem seu raio de atuação, com isso um diálogo mais abrangente com a cultura que ele está inserido promovendo aberturas em suas produções. "Em termos históricos, o grande trabalho do design tem sido ajustar conexões entre coisas que antes eram desconexas." (CARDOSO, 2016. p.44).

Este tipo de perspectiva sobre o olhar do designer para com sua cultura, pensando na articulação de seus artefatos e produções provoca um fomento de novas elaborações e conexões entre seus elementos antes distintos. "As coisas não significam: nós construímos sentido, usando sistemas representacionais - conceitos e signos. " (HALL, 2016. p.48). Ao lançar esse olhar o designer atua de forma distante dos padrões ao mercado editorial vigente, no caso do livro a atender os interesses da padronização e repetição enraizados nas soluções visuais mais convencionais. Provocando o entendimento da recombinação de meios e de que os significados para os objetos são interpretações subjetivas e não fixas a esses objetos, logo podendo ser alteradas, recolocadas e recombinadas. Como reforça Bonfim (1997): 
Não há sentido em objeto sem sujeito, pois o objeto, entendido como “coisa", "fato", "representação", "conceito", "pensamento" etc., só existe dentro dos limites de nossas experiências, de nosso conhecimento e de nossas linguagens. Assim, as características de um objeto são, na verdade, as interpretações subjetivas que dele fazemos. $O$ entendimento sobre um objeto é, portanto, efêmero. Os objetos se transformam, os sujeitos se modificam e os significados dos objetos para os sujeitos também se alteram. (BONFIM, 1997. p.37)

A concepção feita por Gustavo Piqueira em sua produção estimula um diálogo sobre as múltiplas funções que um produto de design pode ter. A discussão acerca do reducionismo que um projeto de design tem de cumprir para se adequar a questões de seus usos é posto à prova. 0 designer aqui relaciona dois meios distintos a suas funcionalidades convencionais cruzando-os em um outro procedimento de atuação, o livro neste momento não é só para se ler e o conjunto de jantar não é mais somente para ser usado em uma refeição. $O$ objeto exibe uma desordem aos padrões dos artefatos de origem. (...) afastar de qualquer solução formal unificadora estética ou eticamente e, portanto, abomina os estilos bem como os discursos hegemônicos, que passam a se construir nas marcas maiores do pensamento contemporâneo (...) (COSTA, 2010. p.16).

A quebra da normatização do design editorial proposta por Piqueira, estabelece segundo o autor, crítico de arte, teórico da mídia e filósofo Boris Groys (1947) exemplificado em seu texto Sobre lo nuevo (2002) um princípio de novo que emerge em seu trabalho. Segundo o autor, o novo atua no campo de que os objetos em sua maioria não são novos, mas sim diferentes por seguirem meramente um princípio de atualização em suas formas e características e não de modificação de suas atuações, proposições e conceitos. Esse paralelo levado a concepção atual de como o novo é projetado atualmente nos leva a observar que toda essa produção a partir de padrões preestabelecidos não possui nada de novo, mas é sim uma mera diferença dos livros produzidos anteriormente.

(..) o novo é uma diferença sem diferença, ou uma diferença além da diferença - uma diferença que não somos capazes de reconhecer porque não está relacionada nenhum código estrutural previamente dado. (GROYS, 2002. p.5).

Alinhando a proposta de Boris com a de Piqueira é possível presenciar esse rompimento com o diferente e o emergir do novo, a partir do princípio de que o projeto LULULUX não possui um padrão e nem um antecessor, improvável de ser comparado a um plano de fundo preexistente, sua abordagem coaduna universos distintos em um objeto único se fazendo uso de um deslocamento de significados, materiais, conceitos e usos. Como reforça Boris: "A produção do novo é apenas um deslocamento de fronteiras entre itens coletados e objetos (...) (GROYS, 2002. p.8). 


\section{LULULUX}

Não haveria, sob o mesmo nome da imagem, diversas funções cujo ajuste problemático constitui precisamente o trabalho da arte? A partir daí, talvez seja possível, em base mais sólida, refletir sobre o que são as imagens da arte e as transformações contemporâneas do lugar que elas ocupam. (RANCIERE, 2012. p.9).

Em LULULUX o conjunto narrativo de jantar possui algumas particularidades nas partes componentes de seu projeto, como é presente em toda abordagem aqui estabelecida onde um objeto ou artificio é usado para mais de uma função, isso irá se repetir a longo da estrutura física projetada. A caixa de LULULUX (figuras 2 e 3 ) por exemplo pode ser entendida a partir de três princípios de seu uso: como uma caixa que agrupa os elementos do conjunto, como uma capa e como o próprio códice do livro. De maneira que as peças não possuem um elemento unificador a fim de reunir e prender o material proposto, a caixa é o ponto central deste agrupamento, os elementos dispersos só são unidos por ela e se caracterizam desta forma ao mais próximo que podemos entender como livro convencional.

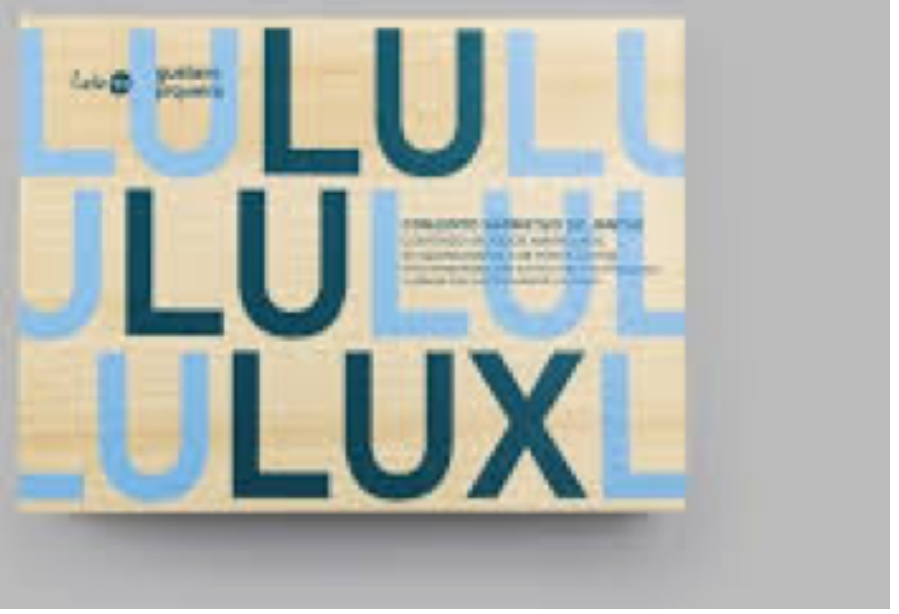

Fig 2. Caixa do livro

Fonte: www.lululux.com.br, 2019

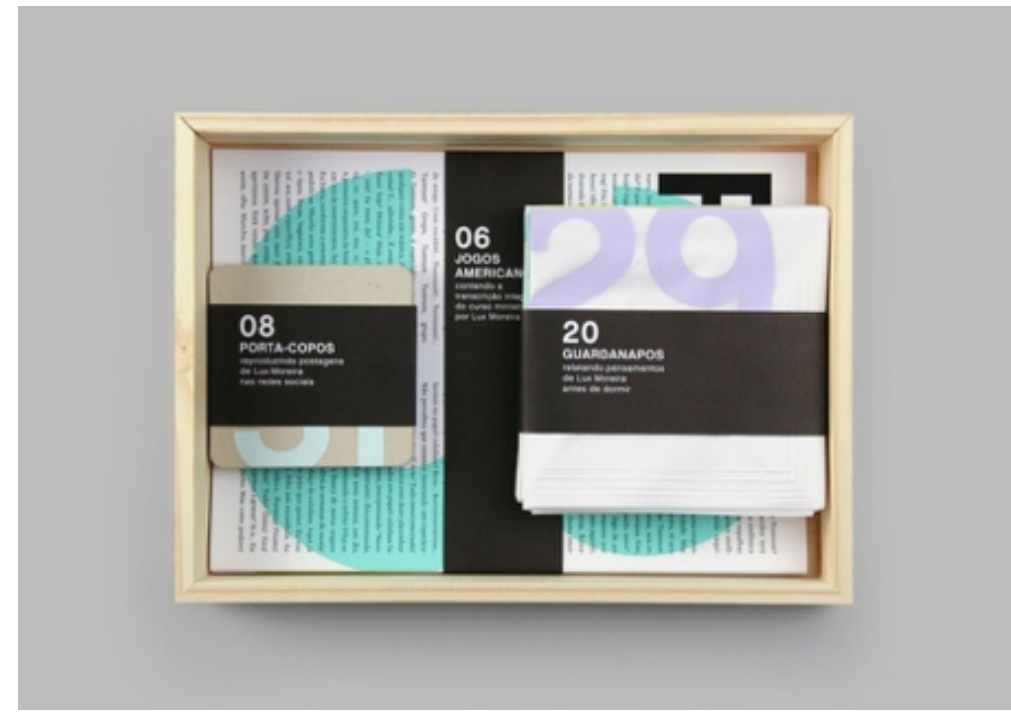

Fig 3. Comportamento do conjunto de peças na caixa Fonte: www.lululux.com.br, 2019

Detecta-se em sua narrativa proposta a história de Lux Moreira (personagem principal), um empreendedor novato que decide ministrar um curso sobre empoderamento para um grupo de funcionários de uma pequena padaria. Lux é a única voz ativa, ele quem narra todas as falas dividida nos três suportes escolhidos mesmo que existam outros personagens na narrativa, mas nenhum participa de forma única, todas as falas escritas são 


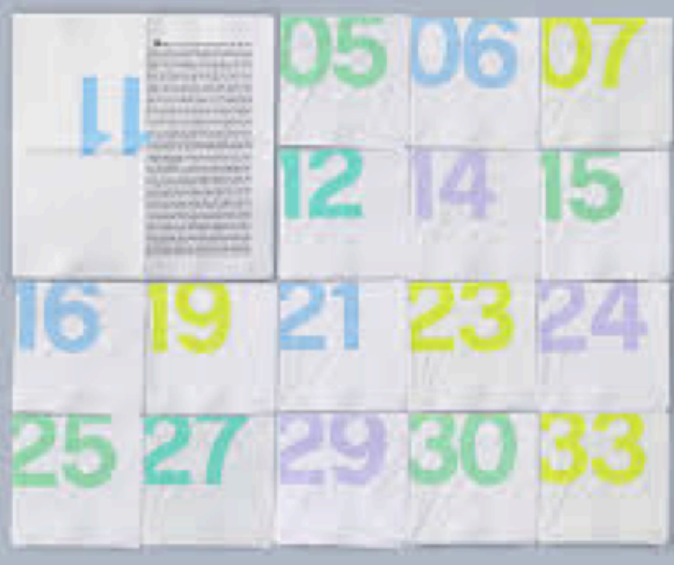

Fig 4. Conjunto de guardanapos

Fonte: www.lululux.com.br, 2019

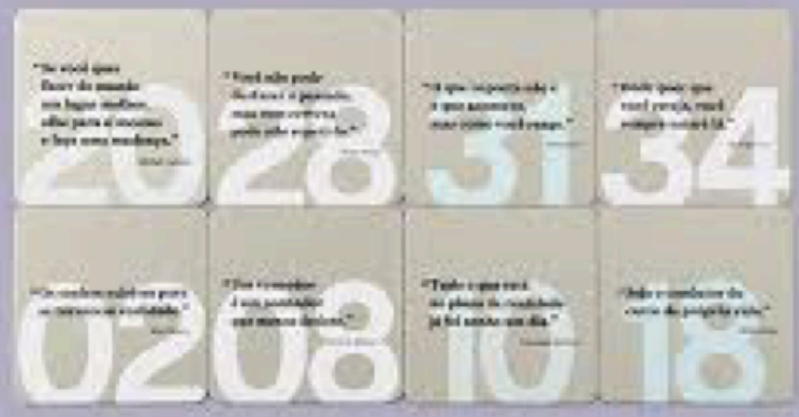

Fig 5. Conjunto de porta copos

Fonte: www.lululux.com.br, 2019

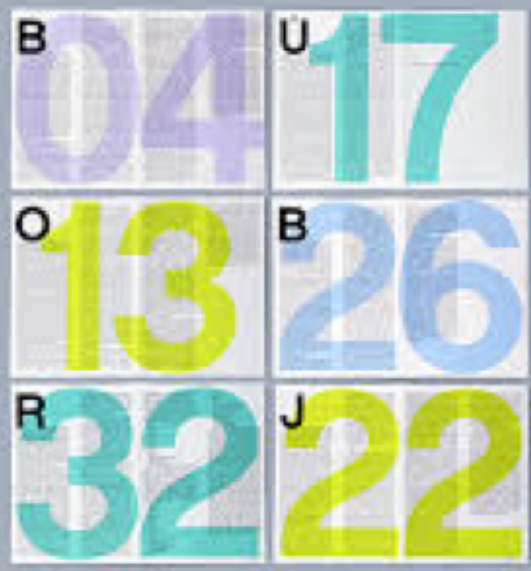

Fig 6. Conjunto de jogo americano

Fonte: www.lululux.com.br, 2019 ditas pelo Lux tornando-se assim um grande monologo deste personagem. Cada suporte para a escrita apresenta uma característica textual, os guardanapos (figura 4) são seus pensamentos, os porta-copos (figura 5) são as postagens nas redes sociais por ele feito e o jogo americano (figura 6) é o curso ministrado.

O sistema de navegação para a leitura pode acontecer de duas formas: se guiando pelos números em ordem agrupando todos os três suportes em uma leitura única ou pode-se ler cada um de uma vez gerando assim uma característica textual e de organização própria. Cada peça possui sua característica individual de escrita, o leitor que optar pelo segundo tipo de abordagem pode ter uma percepção diferente dos eventos que acontecem na história, de acordo com o próprio autor o personagem principal manipula os eventos ocorridos em seu curso que estão localizadas no jogo americano (figura 7) a partir da sua própria percepção do ocorrido. Os guardanapos que são seus pensamentos são estes pontos de vista e as postagens que se apresentam nos porta-copos são uma forma de tentar criar uma imagem que não a real sobre ele como um empreendedor de pseudosucesso. A ordem é embaralhada nas informações de Piqueira, constituindo um tipo de leitura que pode não ser linear da narrativa, mas sim feita através de links entre os objetos componentes.

Os aspectos morfológicos da linguagem visual do objeto se manifestam de forma descomplicada ao leitor, o designer fez uso de duas colunas de mesmo tamanho para distribuir o texto no jogo americano, uma coluna para os guardanapos e de um bloco de texto para os porta-copos afim de estabelecer uma fácil leitura. $O$ uso de capitulares de uma tipografia sem serifa abrem os textos nas peças como demarcação de um início especifico. Ele não se faz uso de nenhum tipo de imagem ao longo do objeto, toda história aqui é desenvolvida a partir do texto escrito que é um elemento característico básico e essencial na construção de um livro. Tudo isso foi impresso em serigrafia devido à restrição que material escolhido no caso o tecido apresenta, de não ser possível se imprimir que não pelo meio serigráfico. A serigrafia expõe um tipo de produção de cunho mais particular por seu desempenho quanto a impressão por não apresentar grande velocidade ou não ser usado para grande quantidade, isso também é reflexo e se valida quando observamos o montante produzido de apenas 600 exemplares. 


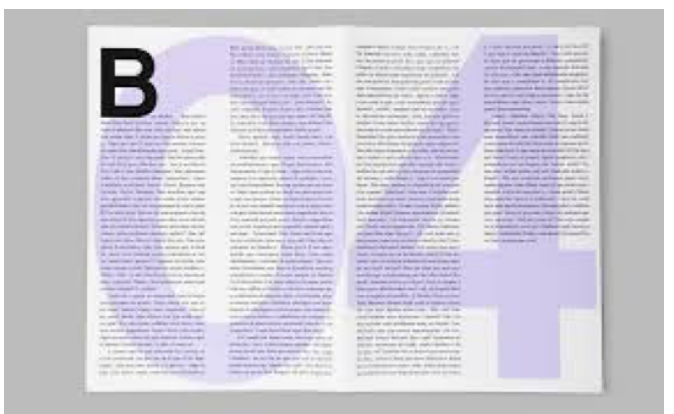

Fig 7. Exemplo de jogo americano Fonte: www.lululux.com.br, 2019
As três cores (roxo, azul e amarelo) escolhidas reforçam tanto o sistema de navegação quanto o de organização dos suportes para o jantar (figuras 8,9 e 10), já que uma das possibilidades desse projeto é estar disposto a mesa de jantar, as cores aqui funcionam também como um esquema harmonioso para se compor a mesa, podendo se fazer uso tanto de um esquema cromático único quanto da combinações entre as três cores, possibilitando uma atuação também de composição do conjunto de jantar em relação aos outros objetos presentes na mesa do usuário.

A proposta de LULULUX que inicialmente segue para ser aplicado a mesa, se comporta mesmo que para organizar um jantar, de forma caótica quando pensamos que uma possível leitura que ainda pode ser feita, tanto a manipulação dos suportes para se ler e a possível interferência dos ingredientes do jantar dificultam a ação do leitor. A efemeridade proposta é um embate a um dos princípios básicos que um livro convencional apresenta de resistir de certa forma a ação do tempo, o uso deste objeto por completo implica a uma fragilidade e efemeridade que o livro não está habituado em sua aplicação, o tornando possivelmente único quando usado por completo.

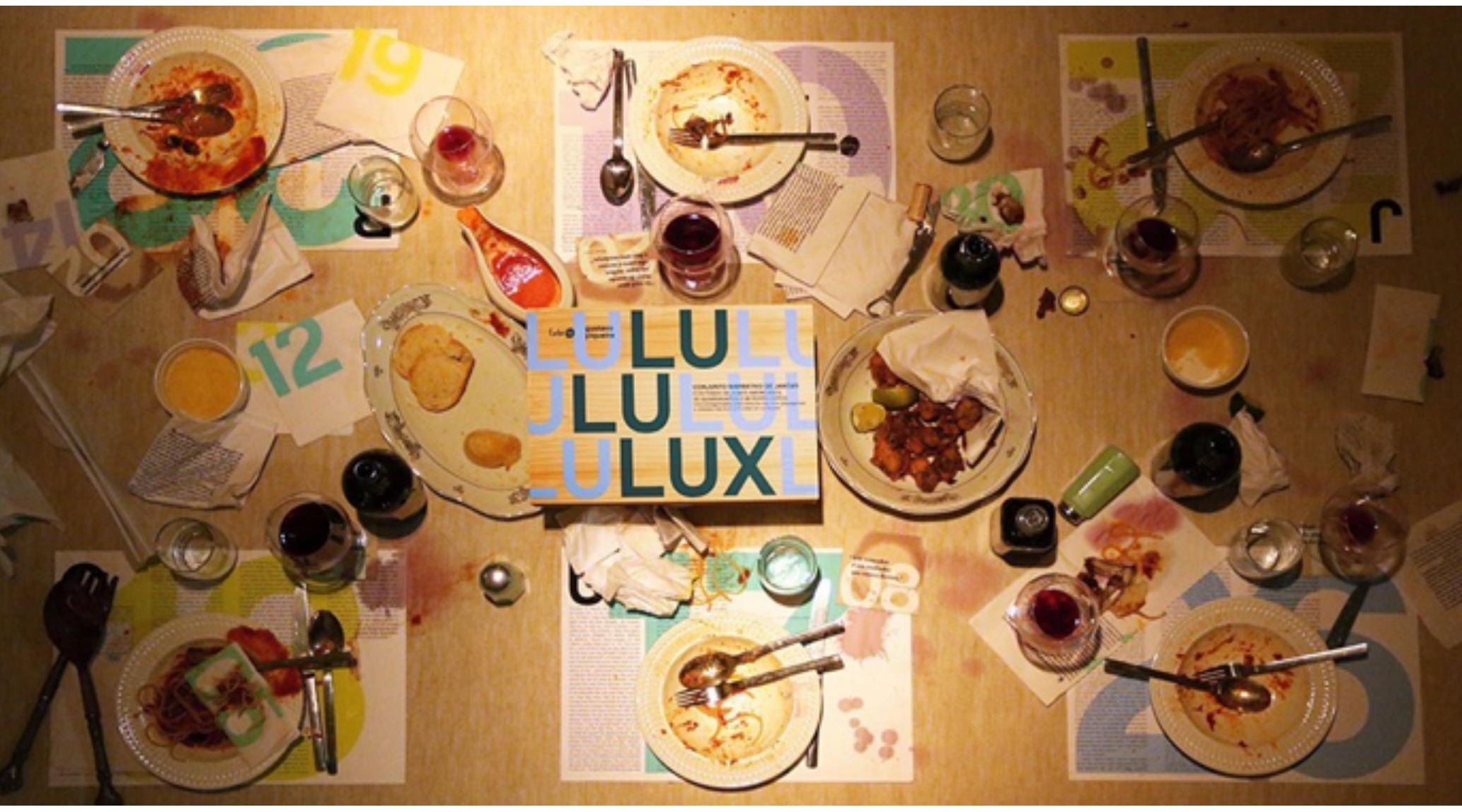

Fig 8. Exemplo do conjunto narrativo de jantar sendo usado no jantar Fonte: www.lululux.com.br, 2019 

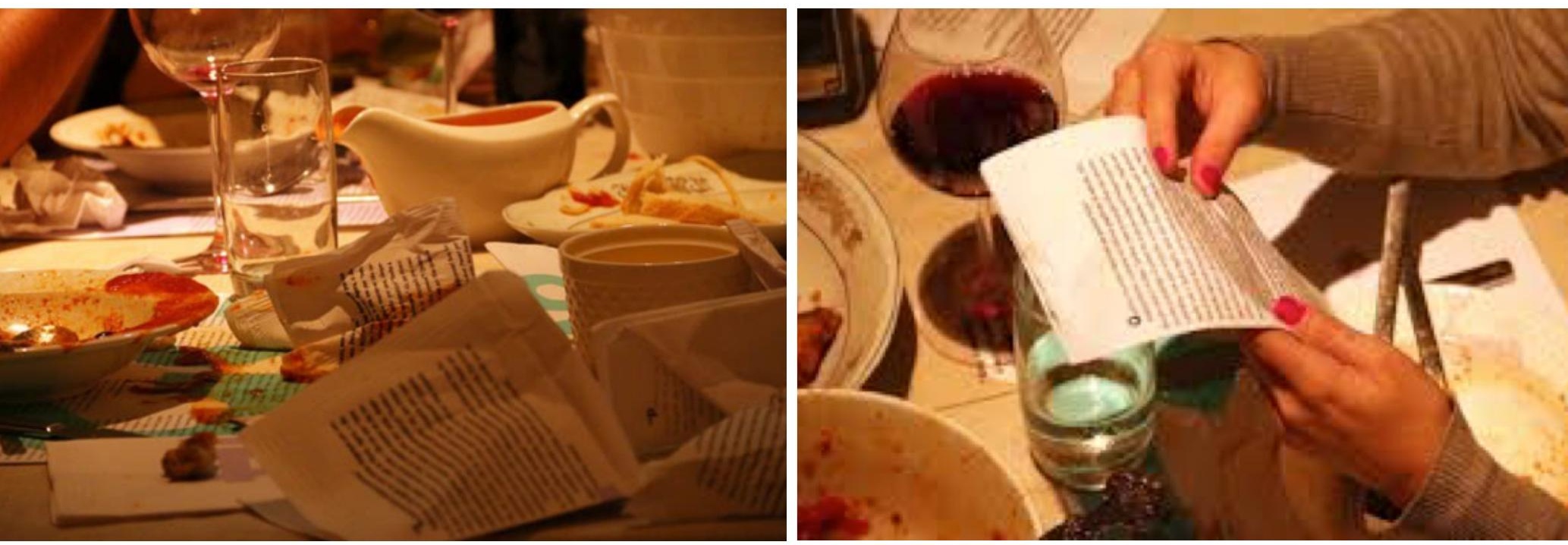

Figs 9 e 10. Exemplo do conjunto narrativo de jantar sendo usado no jantar Fonte: www.lululux.com.br, 2019

\section{Considerações finais}

A investigação feita no artigo constituiu-se na exploração do conjunto narrativo de jantar através da identificação de seus componentes, materiais, linguagem visual e meios de atuação. O levantamento desses dados permitiu a melhor compreensão dos fatos e das abordagens feitas pelo designer, alinhando ao panorama do livro convencional, a abordagem de recombinação de meios do projeto, as múltiplas funções e significados que os objetos podem ter e o princípio de novo e diferente em relação a produção convencional de design editorial, provando toda a potência narrativa e visual presente em LULULUX.

Este projeto é um prisma para as novas abordagens que o design gráfico contemporâneo pode apresentar, expondo a versatilidade que os códigos visuais, materiais e conceituais possuem. Contemplando uma cultura em que estes não estão desconectados, mas que podem ser integrantes de um mesmo universo. A recombinação proposta por Piqueira demonstra toda a potencialidade narrativa que o livro impresso ainda pode ter, explorando as diversas camadas de significados, desdobrando sua materialidade e reestruturando toda uma percepção sobre os objetos do dia-dia, onde está perspectiva de atuação nos leva a compreender toda a potencialidade de desenvolvimento conceitual que o design pode apresentar em um projeto, rompendo barreiras limitantes e expandindo o entendimento sobre o que é um livro e o próprio design gráfico. 
10 jogo americano é uma substituição para a toalha de mesa, ele possui tamanhos menores que a toalha para atender a somente um prato por pessoa.

2 Janelas são recortes específicos feitos para o usuário enxergar a parte de dentro de um objeto.

3 "cultura" ou "cultura material" como o conjunto de artefatos produzidos e utilizados pelas culturas humanas ao longo do tempo, sendo que, para cada sociedade, os objetos assumem significados particulares, refletindo seus valores e referências culturais. (ONO, 2004. p.54).

\section{Referências}

ARANTES, Priscila.; DE OLIVEIRA, Mirtes. Design e Ativismo. DAT Journal, v. 4, n. 2, p. 1-2, 5 Aug. 2019. DOI: https://doi.org/10.29147/dat.v4i2.124

BELLUZZO DE CAMPOS, Gisela; NEDER, Rafael. Visões sobre a Tipografia: aspectos histórico-críticos, metodológicos e tecnológicos. DAT Journal, v. 1, n. 1, p. 1-2, 29 nov. 2016. DOI: https://doi.org/10.29147/dat.v1i1.7

BONFIM, Gustavo Amarantes. Fundamentos de uma teoria Transdisciplinar do design: morfologia dos objetos de uso e sistemas de comunicação. Estudos em design. V. V. n2. dez. 1997. CARDOSO. Rafael. Design para um mundo complexo. Ubu. São Paulo. 2016.

CARDOSO. Rafael. Design, cultura material e o fetichismo dos objetos. Revista Arcos. Volume 1 Rio de Janeiro. 1998.

COSTA. Carlos Zibel. Além das formas: introdução ao pensamento contemporâneo no design, nas artes e na arquitetura. Annablume. São Paulo. 2010.

FALCÃO, Guilherme. AUTO. DAT Journal, v. 4, n. 2, p. 109-111, 5 ago. 2019. DOI: https://doi. org/10.29147/dat.v4i2.135.

GROYS, Boris. Sobre lo nuevo. Artnodes. Universitat Oberta de Catalunya. Catalunya, de esta edición: FUOC, 2002.

HALL, Stuart. Cultura e Representação. Editora PUC-RIO. Rio de Janeiro. 2016.

HASLAM, Andrew. Livro e o Designer II, Como Criar e Produzir Livros. Rosari. São Paulo, 2007. LEOTE, Rosangela; CARVALHO, Agda. Corpo/objeto/espaço. DAT Journal, v. 3, n. 1, p. 1-8, 12 jun. 2018. DOI: https://doi.org/10.29147/dat.v3i1.65

LUPTON, Ellen e PHILLIPS, Jennifer Cole. Novos fundamentos do design. São Paulo: Cosac Naify, 2008.

ONO MISUKO, Maristela. Design, Cultura e Identidade, no contexto da globalização. Revista Design em Foco, vol. I, núm. 1, julho-dezembro, 2004, pp.53-66.

PIQUEIRA, Gustavo. LULULUX. Lote 42. São Paulo, 2015.

RANCIERE, Jacques. $\mathrm{O}$ destino das imagens. Contraponto. Rio de Janeiro, 2012.

ZUANON, Rachel; PRADO, Gilbertto; FERREIRA, Cláudio. Transdisciplinaridades. DAT Journal, v. 1, n. 2, p. 1, 27 dez. 2016. DOI: https://doi.org/10.29147/dat.v1i2.36. 